\title{
$2 p_{1}$
}

\section{$N 64 \quad 10072$ \\ CODE NONE}

T

\section{Some Pressure-Drag Effects of Rounding the Leading Edges of Hypersonic Inlets}

$$
\begin{aligned}
& \text { E. Floyd VAlentine } *^{e} \\
& \text { LASA, Langley Research Center, } \\
& \begin{array}{c}
\text { Hampton, } \frac{\mathrm{Va}}{\text { Langlion, }} \\
\text { Nomenclature }
\end{array}
\end{aligned}
$$

$C_{D, b}=$ round leading-edge drag coefficient

$C_{p, \imath, 2}=$ total pressure coefficient back of a normal shock at $M_{\infty}$

$C_{p, \ell, \beta}=$ total pressure coefficient back of a normal shock at Mach number, $M_{\infty} \cos \beta$

$d / D_{c}=$ ratio of leading-edge diameter to capture area diameter

$d / g=$ ratio of leading-edge diameter to gap of rectangular inlets

$l=$ distance from inlet to outlet

$M_{\infty} \quad=$ freestream Mach number

$\beta \quad=$ sweep angle of a rectangular inlet

$\delta \quad=$ outer-surface cone half-angle

$\theta \quad=$ angle of a normal to the surface measured relative to the freestream direction

Received May 6, 1963.

* Aerospace Engineer. Member AIAA. $\theta_{j}=\begin{gathered}\text { value of } \theta \text { at juncture of the round leading edge with } \\ \text { the straight surface }\end{gathered}$

QTUDIES of the possible performance of external airbreathing engines require an estimation of the powerplant drag that must be subtracted from the computed internal-thrust forces. In this paper an axisymmetric powerplant is at first assumed with an outer surface of conical form terminating at an exit diameter larger than the inlet diameter. Charts for determining pressure drag and skinfriction drag for slender sharp-leading-edged bodies of this type were devised and are presented in Ref. 1 .

In order to be realistic it must be admitted that at hypersonic Mach numbers the leading edge will be rounded to relieve stagnation-point heating. In the present paper, consideration is focused on pressure-drag effects on the rounded leading edge and the pressure-drag effects resulting from changes in pressure further back on the conical surface caused by rounding the leading edge. All computations are for a perfect gas with ratio of specific heats of 1.4.

Estimates were made of the external pressure-drag coeffcients of selected ducted bodies at Mach numbers of 4, 12, and 15. The external pressure drag was considered to consist of the entire leading-edge pressure drag plus the pressure drag on an outer conical surface going from the leading edge back to the exit station. The drag coefficient was based on an inlet area bounded by the center-of-curvature line of the leading edges. 
The leading-edge drag was computed by summing the forces from the modified Newtonian expression for the local pressure coefficient. For equal inner and outer $\theta_{j}$ value, see Fig. 1:

$$
C_{D, b}=4 C_{p, t, 2}\left(d / D_{c}\right)\left(\sin \theta_{j}\right)\left(1-\frac{1}{3} \sin ^{2} \theta_{j}\right)
$$

For $\theta_{j}$ of $90^{\circ}$, this reduces to

$$
C_{D, \delta}=\frac{8}{3} C_{p, \ell, 2}\left(d / D_{c}\right)
$$

Rounding the leading edges would raise the pressures on the outer surface. Figure 3 of Ref. 2 provides means for obtaining a two-dimensional approximation for these pressures. Pressure coefficients were integrated over the outer conical surface to obtain corresponding drag coefficients.

For purposes of this study a value of the hypersonic similarity parameter, $\tan \delta\left(M_{\infty}^{2}-1\right)^{1 / 2}$, of 0.3116 was used and a ratio of exit area to capture area of 3 was assumed. These assumptions produce slender bodies that increase in length as $M_{\infty}$ increases.

The results of the outer-surface, pressure-drag coefficient and the total external pressure-drag coefficient calculations are shown in Fig. 1. The curves show that the leading-edge drag coefficient is high for even small amounts of leadingedge rounding. The effect of leading-edge bluntness on the outer-surface pressure-drag coefficient is minor. For even modest amounts of leading-edge rounding the leading-edge drag is the major portion of the total drag.

The high pressure drag of blunted leading edges may be reduced significantly by sweeping the leading edge; for instance, a rectangular inlet might be incorporated in the swept leading edge of a wing. An analysis was made of a unit

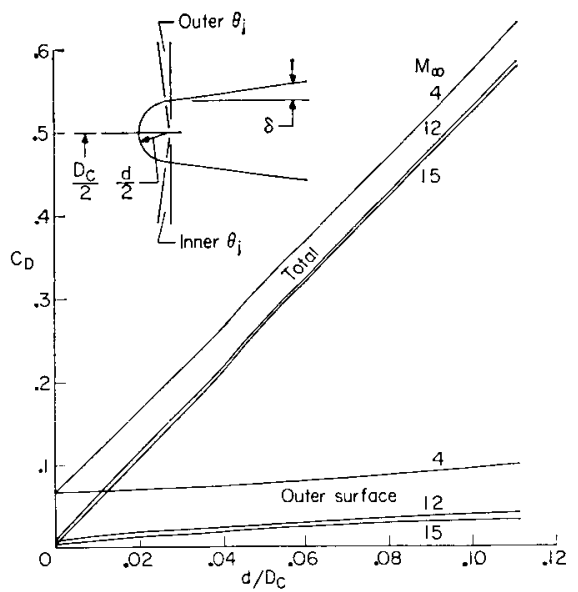

Fig. 1 External pressure-drag breakdown; circular inlets; exit area to capture area ratio $3 ; \tan \delta\left(M_{\infty}{ }^{2}-1\right)^{1 / 2}, 0.3116$; perfect gas.

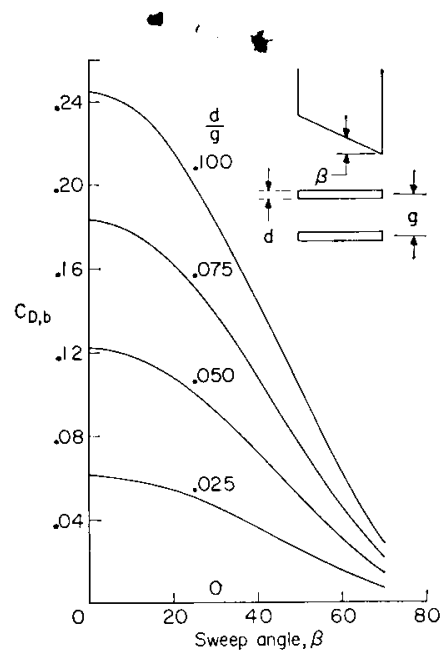

Fig. 2 Leading edge pressure-drag coefficient; semicircular leading edges; modified Newtonian theory; perfect gas; $M_{\infty}=12, M_{\infty}=15$.

length of leading edges and considered only the upper and lower leading edges. The upper and lower circular leading edges were assumed followed by flat surfaces parallel to the freestream. This simplification does not affect the leadingedge pressure-drag coefficient strongly and is justified by a lack of knowledge of the final geometry at this point. The analysis gave the expression

$$
C_{D, b}=\frac{4}{3}(d / g) C_{p, t, \beta} \cos ^{2} \beta
$$

The effect of sweep angle on leading-edge drag coefficient is given in Fig. 2 for freestream Mach numbers of 12 and 15; increasing $M_{\infty}$ from 12 to 15 produced no significant effect on $C_{D, b}$. No consideration of the end boundaries of the rectangular inlets was made. It is probable with long rectangular inlets that intermediate vertical partitions would be required for structural and/or internal-flow considerations. Sweeping the leading edge from $0^{\circ}$ to $70^{\circ}$ reduced the drag coefficient by a factor of about 10 .

In conclusion estimates have shown the increase in total external pressure drag caused by rounding the leading edges of conical ducted bodies to be considerable. Consideration of sweeping the leading edges showed possibilities of markedly decreasing the drag penalty deriving from the necessity of having rounded leading edges.

\section{References}

1 Valentine, E. F., "External-drag estimation for slender conical ducted bodies at high Mach numbers and zero angle of attack," NASA TN D-648 (1961).

2 Baradell, D. L. and Bertram, M. H., "The blunt plate in hypersonic flow," NASA TN D-408 (1961).

\section{CASE FILE COPY}

